\title{
The Prevalence of Contact Dermatitis Among Occupational and Work-related Diseases. Correlation between Atopy and Allergic or Irritative Contact Dermatitis
}

\author{
Pitis Codruta-Dana ${ }^{1 *}$, Tataru Alexandru² \\ 1 University of Medicine and Pharmacy "Iuliu Hatieganu" Cluj-Napoca, Occupational Medicine Clinic Cluj-Napoca, Romania \\ 2 University of Medicine and Pharmacy "luliu Hatieganu" Cluj-Napoca, Clinic of dermatology, Cluj-Napoca, Romania
}

\begin{abstract}
The prevalence of contact dermatitis (CD) in Europe varies between 6.7\% and 10.6\% depending on the sector of activity. Professional CD (PCD) has an important economic impact - 30\% of the budget compensation for occupational disease. In Romania, the prevalence of PCD is underestimated, with an even distribution of cases with respect to the allergic or irritative mechanism. A retrospective clinical study was conducted; target population being the patients admitted in Occupational Medicine Clinic Cluj-Napoca between 2003 and 2011 . Objectives of study were: specifying the prevalence range of allergic CD (ACD) / irritative CD (ICD) among occupational/work-related diseases, the distribution of allergic/irritative $C D(A / I C D)$ for different sectors of activity and establishing the correlation between atopy and A/ICD. We have applied allergy skin tests - prick (environmental allergens) and patch (occupational allergens). Inclusion criteria were: -documented occupational exposure at skin allergens/irritants; -the atopy state; -diagnostic established at discharge. Patients with recurrent chronic urticaria, angioedema, hypereosinophilic syndrome have been excluded. Statistical analysis was done using SPSS software. The study indicated a similar prevalence for A/ICD, with similar distribution. Prevalence above average has been recorded in the metallurgy sector (A/ICD), in health care sector (ACD), respectively, textile industry (ICD). The correlation atopy-ACD has proved to be lower compared to previous reports. Regarding ICD, the diagnostic was confirmed frequently to non-atopic persons. We strongly recommend the compliance with a multidisciplinary protocol for the management of $\mathrm{A} / \mathrm{ICD}$, individualized for specific activity sectors or even work stations.
\end{abstract}

Keywords: contact dermatitis; professional allergens/irritants; atopy; prevalence range

Received: 21 January 2015 / Accepted: 18 July 2015

\section{Introduction}

The European campaign "European Week for Safety and Health at Work 2003 - hazardous substances" tried to draw attention to the great number of potential illness caused by occupational irritative/allergic agents. Sixteen percent of the employees handle hazardous substances daily for the duration of their work program [1]. Due to this exposure, different skin, respiratory, digestive or neurology professional pathologies do appear. In accordance with European Agency for Safety and Health at Work, professional contact dermatitis (PCD) constitute in Europe the main cause for work related health problems, representing $25 \%$ of the total occupational diseases [2]. For CD, professional etiologic factors can have an exclusive triggering role (occupational disease) or just an aggravating/maintenance role (work related disease).

The prevalence of the PCD in Europe varies between $6.7 \%$ and $10.6 \%$ with wide variations depending on the sector of activity (contacts dermatitis of the hand affecting only $2.9 \%$ of civil servants, but $30 \%$ of medical nurses) $[3,4]$. In Romania, the prevalence of PCD is underestimat- ed due to the fact that not all the cases of illness produced by occupational exposure are reported [5,6]. Both in Europe and in the USA, economic impact of this pathology is emphasized by the fact that $30 \%$ of the budget compensation dedicated to occupational diseases $[5,7,8]$ is granted to persons diagnosed with $\mathrm{PCD}$. As regard to forms of allergic CD (ACD), respectively, irritative CD (ICD), European statistics are tipping the balance in favour of ICD [3]. In our country, the distribution depending on the allergic or irritative pathogenic mechanism showed no significant difference [5].

To supplement the information relating to occupational skin pathology in Romania, in particular the data related to the ACD and ICD, we have undertaken a retrospectively clinical study using as target population the patients admitted in the Occupational Medicine Clinic Cluj-Napoca during the period January 2003 to December 2011.

Objectives of study consisted in specifying:

- the prevalence range of A/ICD among occupational diseases and work related diseases, and

- the distribution of cases of A/ICD on the various sectors of activity, with identification of those jobs where there is a significant occupational exposure to skin allergens or irritants. 
Additionally, there has been assessed the correlation between genetic predisposition (atopic status) and the appearance of ACD, respectively, ICD.

\section{Material and Method}

The retrospective study undertaken referred as start point the data recorded in the observation sheets from the archives of Occupational Medicine Clinic Cluj-Napoca, during the period January 2003 - December 2011. At admission, patients included in the study signed an informed consent agreement (document which has become part of the observation sheet). Regarding the establishment of the ACD, respectively, the ICD positive diagnosis, the recommendations of the European Society of Allergology and Clinical Immunology [9] were applied. Patients included in the study have been examined clinically and tested in collaboration with dermatologist practitioners within the University Clinic of Dermatology Cluj-Napoca. In order to select the groups of patients, the following criteria for inclusion have been used:

- documented occupational exposure at skin allergens or irritants (field of activity, professional risk factors - information taken from occupational history, exposure to risks worksheet and professional book);

- atopic status (positive family and personal allergic antecedents, increased serum levels of total $\operatorname{IgE}$ and Eosinophil granulocytes, allergy skin prick tests using habitual allergens);

- discharge diagnosis (PCD or CD with professional maintenance/aggravation factors; diagnosis was established based on dermatology clinical examination and on application of patch tests using allergens specific for the workplace).

The patients who at the end of the period of hospitalization have been categorized as having chronic recurrent rash/urticaria, angioedema, hypereosinophilic syndrome or drug allergic skin reaction have been excluded from the study.

By applying all the above criteria two groups of patients were obtained - patients diagnosed with ACD (50 patients), respectively, patients diagnosed with ICD (42 patients). Both groups have had exposure to occupational agents with allergic and/or irritative reactions. For both groups the presence of atopy was investigated.

In order to specify the division of PCD cases during the survey period (the first declared objective of the study), the range prevalence for A/ICD has been calculated both for occupational and work related diseases. We have decided to determine the range prevalence as statistic parameter (total number of workers affected by PCD in a given period) since, in the case of $\mathrm{PCD}$ which is often a chronic pathology, this statistic parameter brings additional information as compared with the incidence (number of new diagnosed diseases), respectively, the prevalence of point (total number of workers affected by PCD at a given time). By calculating the range prevalence, patients with recur- rent $\mathrm{CD}$, as well as recent cases of illness are included ${ }^{(4)}$. The plot chosen was the line type and we have calculated both average, standard deviation for expressing the dispersion of data, the degree of symmetry (SKEW), the KURT coefficient, as well as the coefficient of correlation.

Distribution of A/ICD cases for the various sectors of activity (second aim of the study) had been reached by the generation of column type graphics. The average of prevalence has been calculated, being appreciated as sectors of activity with significant occupational exposure to skin allergens or irritants, those areas for which the prevalence of PCD has been at least equal to the calculated statistics average. Determination of the SKEW degree of symmetry additionally offered an overall picture of all those sectors of activity with A/ICD prevalence above average. An allergy/ irritative comparative graphic have been also generated with regard to range prevalence of the two pathologies for different industries specific for the patients included in the study. At the same time, covariation and the coefficient of correlation were calculated.

Correlation between genetic predisposition (atopic status) and the diagnostic of ACD, respectively, ICD has been explained by pie type graphics for the percentage expression, respectively, by column type graphics when the data were referred as numbers. Covariation and the coefficient of correlation were used to analyse the relationship between atopy and diagnostic of ACD, respectively, ICD.

Raw data has been collected in a spreadsheet file, statistical calculation being carried out using the software SPSS.

\section{Results}

The results of the study have shown a period prevalence similar for the two pathologies (see Figure 1), with a uniform distribution of cases for the period concerned (SKWE degree for $\mathrm{ACD}=0.21$, for $\mathrm{ICD}=0.46$, and comparative $\mathrm{ACD} / \mathrm{ICD}=0.32$ ). The calculated value of the correlation coefficient $(0.68)$ indicates a good correlation, the two pathologies having a similar behaviour. Also, for both series it was noted a high degree of dispersion $(3.15 \mathrm{ACD}$, respectively, 2.77 ICD), with a distribution of the annual number of $\mathrm{CD}$ cases away from average.

Annual tendency between 2003 and 2011

$$
- \text { ACD }- \text { ICD }
$$

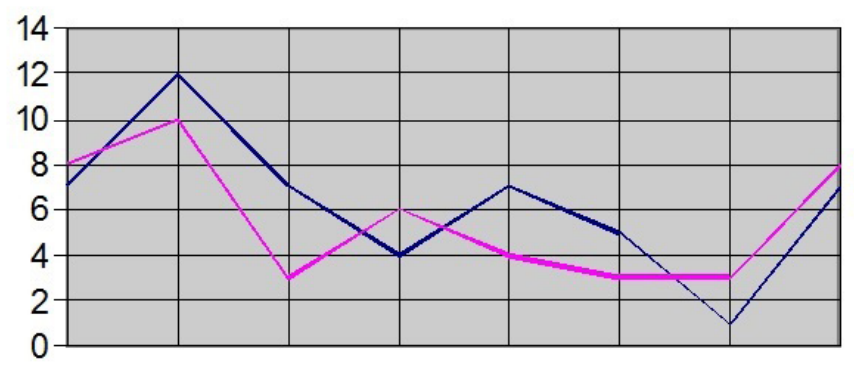

Fig. 1. The period prevalence for cases of ACD and ICD. Annual tendency between 2003 and 2011 
During the survey period, all the above mentioned statistical parameters suggest a similar behaviour for the two types of CD.

As regards to the distribution by sectors of activity for the studied illness cases, a prevalence increased much above average has been obtained (average $\mathrm{ACD}=6.25$, average $\mathrm{ICD}=5.63)$ :

in the metallurgy sector (both ACD and ICD were above average),

in health care sector (for ACD), respectively, in the textile industry (ICD).

Figure 2 illustrates distribution of A/ICD by sectors of activity, with demonstration of other industries with an increased prevalence, namely: wood manufacturing, shoes manufacturing (ACD) and the chemical industry (ICD).

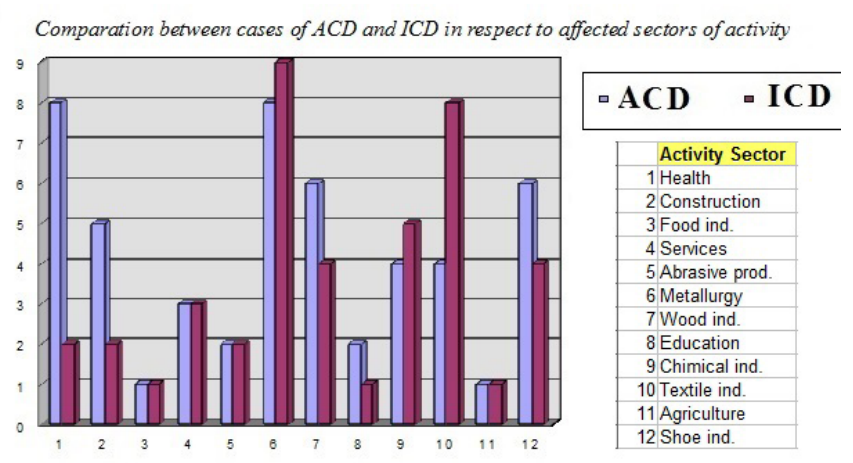

Fig. 2. Distribution by sectors of activity for cases of ACD and ICD

Calculated value of correlation coefficient between the series of the two types of dermatitis and the various sectors of activity (correlation coefficient $=0.55$ ) revealed a correlation slightly above average. This shows that the certain occupational sectors are teaming up with either allergic contact dermatitis, either with the appearance of irritative type lesions.

As regards to the third objective of the study, the correlation between atopy and ACD has proved to be not so strong compared with the data reported by literature ${ }^{(10)}$. The current study identified however the presence of atopy in $54 \%$ of analysed ACD cases.

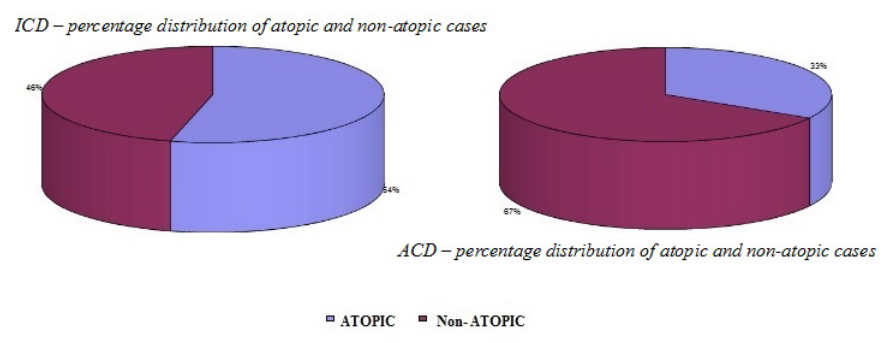

Fig. 3. Presence of atopy among individuals diagnosed with ICD, respectively, ACD
In addition, when atopy is a pre-existing condition, ACD is more probably to appear, not the irritative form of dermatitis. Thus, of the total persons exposed to skin occupational risk factors and diagnosed as having atopy, a greater percentage (65.85\%) develop ACD. Also, quantification of the relation atopy-ACD by determining the correlation coefficient (determined value $\mathrm{ACD} /$ atopy $=0.61$ ) demonstrates that there is a high risk for occurrence of allergic, not irritative lesions to patients having atopy.

With regard to the cases of ICD, the diagnosis was frequently confirmed to persons not having atopy (67\%), atopy acting rather as a factor of protection, not etiological one. The correlation atopy-ICD is negative, a fact stressed also by determination of the correlation coefficient (determined value $\mathrm{ICD} /$ atopy $=0.23$ ).

\section{Discussions}

The study undertaken can be labelled as a small scale study as regards to the groups of patients observed (92 patients). However, what lets us extrapolate the data obtained from the current study to the general population of persons exposed to irritative and/or allergic occupational agents is the fact that target population is represented by patients hospitalized for a period of 8 years in the Occupational Medicine Clinic Cluj-Napoca, pole of the profile services at regional level.

The first important aspect to be specified is the chart obtained by statistical processing of data related to the period prevalence of ACD and ICD. This chart indicates a similar prevalence for the two pathologies. Medical literature tips the balance in favour of ICD [11]. This difference may be explained by the increased medical addressability present for the patients with allergic type lesions. This tendency is due to the clinical panel typical for ACD (including the presence of itching, symptom deeply disturbing in relation to social or professional relationships and quality of life). It is also due to the more serious potential of ACD to become chronic and to the grater rate of recurrence that this pathology has, including, in time, the phenomena of extension of the affected skin [12].

The fact that the metallurgical industry sector is frequently a nest for both forms of allergic and irritative types of contact dermatitis is one of the original aspects revealed by the undertaken research study. The second workplace in respect to increased prevalence of professional $\mathrm{CD}$, similar to the articles in European medical literature, is the health care sector ${ }^{(3)}$. An additional remark concerning the health care sector refers to the high impact of the frequent exposure to irritative/allergic agents. Thus, the lesions of professional CD were more expressed when the doctors or nurses were frequently in contact with even little quantities of irritative/allergic agents, compared with the case of intense, but limited, rare exposures.

The predominance of irritative lesions in the chemical industry is a fact also described previously by other authors 
[3], combination of irritative effect with mechanical stress being a possible explanation.

The correlation atopy-ACD is a topic also described in other medical articles. The novelty of the current study and of the statistic processing derives from the exact statistical quantification of this correlation (determination of the correlation coefficient between atopy and ACD). In addition, the undertaken study investigated and quantified also the relationship between the atopic status and the emergence of ICD lesions.

\section{Conclusions}

In conclusion, we strongly recommend the compliance with a multidisciplinary protocol for diagnosis with a view to correctly and completely identify the number and type of illnesses caused by exposure to irritative and/or allergic skin agents in occupational environment. We support the findings of other scientific studies [8] relating to the need for carrying out a study at the national level in order to bring additional information, useful for occupational medicine practice, for diagnosis, prophylaxis and treatment of contact dermatitis. It would be also useful to clearly specify those valid steps in the management of ACD and ICD for each sector of activity or work station. Carrying out a study at very large scale can be supported by employers, who are forced by law to adopt all the necessary measures to avoid adverse effects of toxic occupational agents on workers' health. Involvement of employers can be obtained through the emphasis of connection between controlling risks at the workplace (implementation of efficient plans for safety and health at work) and having a successful business (higher moral of the staff, enhanced productivity, reduced quantities of raw materials).

\section{Acknowledgement}

In the development of this article, has contributed work of administrative staff Clinic of Occupational Medicine, without it the processing of information from the observation sheets would have been very difficult. Special thanks must be addressed to the specialists of the University Clinic of Dermatology Cluj-Napoca, clinical examination and application of skin tests being the result of their support. We must also refer to the work carried out with a view to statistical processing of raw data - work carried out under the guidance of Mr. Trana Dan Mircea, Ph.D., associated professor at University "Spiru Haret” Bucharest, Faculty of Accounting and Finance.

The authors mention that there are no potential conflicts of interest in respect to the development, drafting or publication of this article.

\section{References}

1. Fundația Europeană pentru Îmbunătățirea Condițiilor de Viață și Muncă Al treilea studiu european privind condițiile de lucru (Dublin) 2000.

2. John $\mathrm{SM}$. Campania europeană de prevenție «O piele sănătoasă la locul de muncă» - healty skin@work, Academia Europeană de DermatoVenerologie (EADV) 2010

3. Bordel-Gómez MT, Miranda-Romero A, Castrodeza-Sanz J. Epidemiology of contact dermatitis: prevalence of sensitization to different allergens and associated factors. Actas Dermosifiliogr, 2010;1012:196.

4. Belsito DV. Occupational contact dermatitis: Etiology, prevalence, and resultant impairment/disability. J Am Acad Dermatol, 2005;532:303-313.

5. Statescu L, Branisteanu D, Dobre C, et al. Contact DermatitiEpidemiological Study. Maedica, 2011;6:277-281.

6. Todea A, Ferencz A. Morbiditatea profesională în România în 2007. Registrul operativ național al bolilor profesionale,2008;39:63-64.

7. Raison-Peyron N. Le diagnostic des eczemas professionnels. Revue francaise d'allergologie et d'immunologie clinique, 2006;46:45-50.

8. Diepgen TL, Weisshaar E. Contact dermatitis: epidemiology and frequent sensitizers to cosmetics. J Eur Acad Dermatol Venereol, 2007;21: 9-13.

9. European Society of Contact Dermatitis. Irritant contact dermatitis and Allergic contact dermatitis: Diagnostic tests. http://www.escd.org/aims/ contact_dermatitis

10. Bucur G, Bucur L, Sălăvăstru C, Țiplica GS. Clasificarea dermatitei de contact ortoergice. Dermatita atopică, în Dermatoze profesionale. editura Niculescu, București, 2006, 86-91, 99-100.

11. Bucur G, Bucur L, Sălăvăstru C, Țiplica GS. Dermatita de contact iritativă, în Dermatoze profesionale. editura Niculescu, București, 2006; 81.

12. Bucur Ghe, Bucur L, Sălăvăstru C, Țiplica GS. Criterii de diferențiere între dermatita iritativă și cea alergică, în Dermatoze profesionale. editura Niculescu, București, 2006; 93. 